\title{
Voltage Dip Ride-Through Capability of Converter-Connected Generators
}

\author{
Bert Renders, Koen De Gussemé, Lieven Degroote, Bart Meersman and Lieven Vandevelde \\ Ghent University, Electrical Energy Laboratory (EELAB), \\ Department of Electrical Energy, Systems and Automation (EESA), Gent, Belgium. \\ Email: Bert.Renders@UGent.be
}

\begin{abstract}
Voltage dips have been proven to be one of the most important aspects of power quality. In order to avoid major economical damage, grid-connected equipment should be designed with a good voltage dip immunity. This holds as well for converter-connected loads as for converter-connected distributed generation (DG) units. This paper presents a control strategy for grid-connected DG converters yielding an improved voltage dip ride-through capability. Due to the implementation of the proposed control strategy, shutdown of DG units due to voltage dips is avoided, resulting in a stronger utility grid. Experimental tests on a single-phase full-bridge bidirectional converter are carried out and validate the aforementioned postulations.
\end{abstract}

\section{Key words}

Voltage Dips, Voltage Dip Ride-Through Capability, ACDC power converters

\section{Introduction}

Voltage dips are short decreases in rms voltage caused by a short-duration increase in grid current due to motor starting, transformer energizing or faults in the electric supply system. Voltage dips have been proven to be one of the most important aspects of power quality $[1,2]$.

The need to reduce the effects of voltage dips is dependent on the amount of equipment with a high sensitivity for grid disturbances. The presence of sensitive gridconnected power-electronic equipment has increased a lot over the past decades. In order to reduce the consequences of grid voltage dips, two strategies are possible. On the one hand, this can be accomplished by increasing the voltage dip immunity of sensitive equipment $[3,4]$. On the other hand, improvement of the support of the utility grid given by grid-connected distributed generation (DG) units proves to be a complementary solution $[5,6]$. With most of the solutions to increase voltage dip immunity at the load side, the converter absorbs additional line currents from an already weakened grid. Therefore, the power injected by DG units could make the difference between recovery and instability.

The growing interest in environmental issues, combined with the progress of technologies to couple renewable energy sources to the grid and the liberalization of the en-

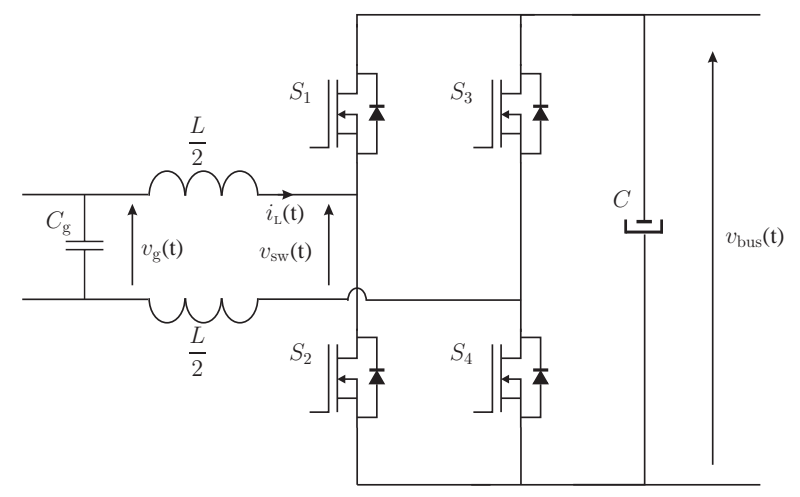

Figure 1: Topology of the full-bridge bidirectional converter

ergy market have led to a growing share of grid-connected DG. The primary energy sources most often used in these small-scaled applications are wind, solar power, small combined heat and power units, fuel cells and hydro power. In spite of the growing number of DG units, their contribution of power delivered to the utility grid remains small, as compared to the power injected by the large centralized power plants.

Therefore, the voltage dip immunity of DG units has not received much attention in the past. Moreover, many grid operators demand the immediate shutdown of DG in case of grid disturbances as prerequisite for grid connection. However, as the power generated by DG units increases, this behaviour stresses the utility grid and may cause power unbalance, which may turn into instability. In order to achieve a sustainable grid reliability combined with large penetration of DG, some grid operators already require voltage-dip ride-through capability [7].

\section{Control strategy}

In this paper, the behaviour of converter-connected DGunits during voltage dips will be investigated. The topology of the utilized full-bridge ac-dc bidirectional converter is depicted in Fig. 1. The converter consists of an EMIfilter (represented by capacitance $C_{\mathrm{g}}$ ) on the ac-side of the converter, and a boost-type full-bridge converter with two input inductors $\frac{L}{2}$, switches $S_{1}$ to $S_{4}$, and a buffer capacitor $C$ at the dc-side of the converter. The converter is controlled by means of a digital signal processor (DSP). 


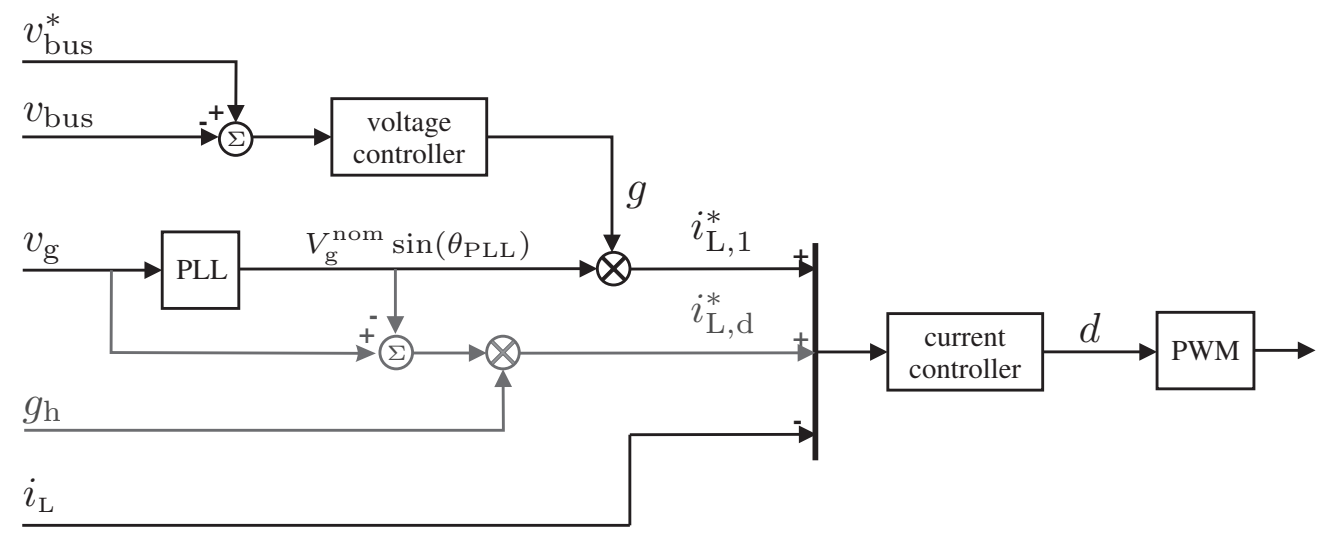

Figure 2: Control strategy for a grid-connected converter. Black lines: sinewave converter, black and grey lines: converter with programmable damping resistance.

The measurements necessary for the control of the converter are the inductor current $i_{\mathrm{L}}(t)$, grid voltage $v_{\mathrm{g}}(t)$ and bus voltage $v_{\mathrm{dc}}(t)$. These quantities are used by the digitally implemented controller to calculate the duty-ratio $d$. The PWM signals are calculated based on this duty ratio and are presented to the switches of the full-bridge converter.

As stated in section 1., most commercial available gridconnected converters shape the injected line currents as perfect sinewaves. This type of current controller can be found in almost all commercially available DG converters [8]. The corresponding control algorithm is depicted in Fig. 2 (black lines only).

The depicted control scheme uses two controllers: a bus voltage controller and an inductor current controller. The output voltage controller obtains a constant bus voltage by changing the fundamental input conductance $g$. This prescribes the amplitude of the reference value for the inductor current $i_{\mathrm{L}}^{*}$ and thus the amount of fundamental power exchanged with the grid. The reference value for the inductor current $i_{\mathrm{L}}^{*}$ is the product of the emulated fundamental conductance $g$ and a sinusoidal reference signal $\sin \left(\theta_{\mathrm{PLL}}\right)$ :

$$
i_{\mathrm{L}}^{*}=g \sin \left(\theta_{\mathrm{PLL}}\right) .
$$

The phase $\theta_{\mathrm{PLL}}$ of the sinusoidal reference signal is locked to the phase of the fundamental component of the mains voltage by using a standard phase-locked loop (PLL).

The second current controller is designed to shape the grid currents in a more complex way. The inductor current is constructed from two parts. The available DG power is transferred into the utility grid using a sinewave with variable amplitude, as does the classical current controller. Then, another current waveform is superposed on this sinewave, as can be seen below:

$$
i_{\mathrm{L}}^{*}=g \sin \left(\theta_{\mathrm{PLL}}\right)+g_{\mathrm{h}}\left(v_{\mathrm{g}}-\sin \left(\theta_{\mathrm{PLL}}\right)\right) .
$$

Since $\theta_{\mathrm{PLL}}$ is locked to the phase of the fundamental component of the mains voltage, this equation can be simpli- fied to:

$$
\begin{aligned}
i_{\mathrm{L}, n}^{*}= & g_{1, n} \sin \left(\theta_{\mathrm{PLL}, n}\right)+g_{\mathrm{h}, n}\left(\left|v_{\mathrm{g}, 1, n}\right|-1\right) \sin \left(\theta_{\mathrm{PLL}, n}\right) \\
& +g_{\mathrm{h}, n} v_{\mathrm{g}, \mathrm{h}, n} .
\end{aligned}
$$

Where $v_{\mathrm{g}, 1, n}$ and $v_{\mathrm{g}, \mathrm{h}, n}$ are the digital representation of the fundamental component and the harmonic content of the grid voltage respectively. The first term of this equation, can be interpreted as the steady-state value of the fundamental component of the inductor current. This term is adapted by the bus-voltage controller in order to balance the power exchanged with the utility grid. Since the voltage controller is slow, $g$ is slowly varying. The second term of the equation is swiftly varying, as it will react on every deviation of the fundamental grid voltage $v_{\mathrm{g}}$ from its steady-state value.

The current originating from voltage disturbances is determined by the programmable damping resistance $g_{\mathrm{h}}$. This conductance is chosen maximal (viz $1 \mathrm{pu}$ ) to retain the maximal damping potential. This control strategy damps grid disturbing phenomena, and was investigated with respect to harmonic oscillations in the utility network [9]. The obtained input impedance of the bidirectional fullbridge converter was thoroughly analysed in [10].

\section{Instantaneous response to voltage dips}

The instantaneous response of the converter to voltage dips is independent of the bus voltage controller. In other words, for short-time voltage dips the fundamental conductance $g$ can be treated as a constant value.

The grid voltage and the inductor currents of the converter with control strategies as discussed in section 2. during a $30 \%$ voltage dip are depicted in Fig. 3 as gray and black lines respectively. The plots are made by using an experimental full-bridge converter for DG applications. The dashed black line represents the grid current of the sinewave converter. The grid current remains unchanged during the voltage dip, as could be expected based on (1). The full black line represents the grid current of the converter with 


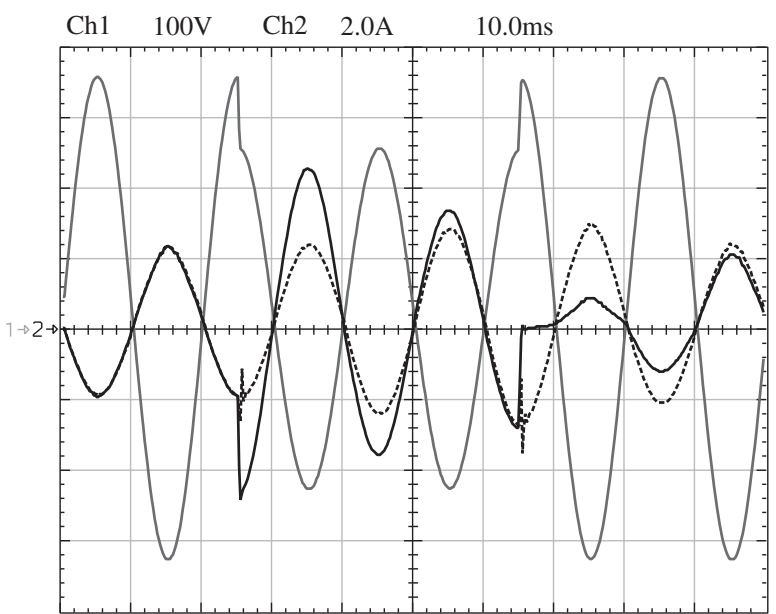

Figure 3: Grid voltage and grid currents during a 30\% voltage dip.

Gray line: grid voltage, full black line: inductor current of the converter with programmable damping resistance, dashed black line: inductor current of the sinewave converter.

programmable damping resistance. The grid current increases instantaneously at voltage dip initiation (2). In Fig. 3, a transient phenomenon can be discerned. Due to the immediate change of the grid voltage $v_{\mathrm{g}}$, an unbalance is created between $v_{\mathrm{g}}$ and $v_{\mathrm{sw}}$. Since the current controller is not ideal, the inductor current increases until $v_{\mathrm{sw}}$ is adapted by the current controller. This effect can be discerned well in the inductor current of the sinusoidal converter (dashed black line). This effect cannot be noticed in the inductor current of the converter with programmable damping resistance. However, the effect is present but is concealed by the amplitude variation of the set value of the inductor current.

The main reason for converter-connected DG-units to disconnect during voltage dips, is an excessive bus voltage $v_{\mathrm{dc}}$, which causes a trip of the corresponding protection relay and the immediate shutdown of the converter. The bus voltage can be calculated by the charge balance of the bus capacitor $C$, and is dependent of the power injected in the utility grid $P_{\mathrm{ac}}$ and the power delivered to the converter by the DG power source $P_{\mathrm{dc}}$.

$$
P_{\mathrm{ac}}(t)+P_{\mathrm{dc}}(t)=\frac{C}{2} \frac{d v_{\mathrm{dc}}^{2}(t)}{d t},
$$

The converter is supposed to be in steady-state just before the dip, or in other words $\left|P_{\mathrm{dc}}\right|=\left|P_{\mathrm{ac}}\right|$, and $P_{\mathrm{dc}}(t)$ is considered to be constant during the voltage dip. Integration of this equation from the start of the dip at $t=0$ over the dip duration $t_{\text {dip }}$, results in:

$$
\int_{0}^{t_{\mathrm{dip}}} P_{\mathrm{ac}}(t) d t+P_{\mathrm{dc}} t_{\mathrm{dip}}=\frac{C}{2}\left(v_{\mathrm{dc}}^{2}\left(t_{\mathrm{dip}}\right)-v_{\mathrm{dc}}^{2}(0)\right) .
$$

For a sinewave converter undergoing a grid voltage dip with dip magnitude $D, P_{\mathrm{ac}}(t)$ can be written as:

$$
\begin{aligned}
P_{\mathrm{ac}}(t) & =v_{\mathrm{g}}(t) i_{\mathrm{L}}(t) \approx v_{\mathrm{g}}(t) i_{\mathrm{L}}^{*}(t) \\
& \approx g(1-D)\left|v_{\mathrm{g}}\right|^{2} \sin ^{2}\left(\theta_{\mathrm{PLL}}\right) \\
& \approx(D-1) P_{\mathrm{dc}}+\frac{g(1-D)\left|v_{\mathrm{g}}\right|^{2}}{2} \sin \left(2 \theta_{\mathrm{PLL}}\right)
\end{aligned}
$$

Where the last term of the equation represents the $100 \mathrm{~Hz}$ variation of the transferred power. In order to express the bus voltage increase in function of the grid voltage dip independently of the bus voltage ripple, $t_{\text {dip }}$ is chosen as a multiple of half the grid period. This allows to simplify (5) combined with (6) to:

$$
v_{\mathrm{dc}}^{2}\left(t_{\mathrm{dip}}\right)=v_{\mathrm{dc}}^{2}(0)+\frac{2}{C} D P_{\mathrm{dc}} t_{\mathrm{dip}} .
$$

For a converter with programmable damping resistance undergoing a grid voltage dip, $P_{\mathrm{ac}}(t)$ can be written as:

$$
\begin{aligned}
P_{\mathrm{ac}}(t) & =v_{\mathrm{g}}(t) i_{\mathrm{L}}(t) \approx v_{\mathrm{g}}(t) i_{\mathrm{L}}^{*}(t) \\
& \approx(1-D)\left(g-D g_{\mathrm{h}}\right)\left|v_{\mathrm{g}}\right|^{2} \sin ^{2}\left(\theta_{\mathrm{PLL}}\right) \\
& \approx(D-1) P_{\mathrm{dc}}+\frac{1}{2}(D-1) D\left|v_{\mathrm{g}}\right|^{2} g_{\mathrm{h}} \\
& -\frac{(1-D)\left(g-D g_{\mathrm{h}}\right)\left|v_{\mathrm{g}}\right|^{2}}{2} \sin \left(2 \theta_{\mathrm{PLL}}\right)
\end{aligned}
$$

Considering the preassumption made for $t_{\mathrm{dip}}$, (5) combined with (8) can be simplified to:

$$
\begin{aligned}
v_{\mathrm{dc}}^{2}\left(t_{\mathrm{dip}}\right) & =v_{\mathrm{dc}}^{2}(0) \\
& +\frac{2}{C}\left(D P_{\mathrm{dc}}+\frac{1}{2} D(D-1) g_{\mathrm{h}}\left|v_{\mathrm{g}}\right|^{2}\right) t_{\mathrm{dip}}
\end{aligned}
$$

Based on Fig. 3 and equations (6) and (8), the influence of the control strategy on the power exchanged with the utility grid can be deduced. These results are dependent on the power flow direction. For DG applications the following results are obtained. The sinewave converter undergoing a voltage dip exchanges less power with the grid compared to the situation before the voltage dip. The resulting power excess at the dc-side of the converter is absorbed in the bus capacitor, resulting in a significant bus voltage rise. The power of the converter with programmable damping resistance is not always decreased during the voltage dip. If $P_{\mathrm{dc}}<(1-D) P_{\text {nom }}$ the transmitted power is increased, resulting in a power shortage at the converter bus and a concomitant bus voltage drop.

The average bus voltage variations, described by (7) and (9), are plotted in Fig. 4 for a dip duration $t_{\text {dip }}$ equal to 1.5 net periods $(30 \mathrm{~ms})$ in a $50 \mathrm{~Hz}$ grid. This dip duration can be considered as the worst case situation, as it corresponds with the experimentally verified peak response of the bus voltage. As can be seen in Fig. 4, the implementation of the control strategy for a programmable damping resistance yields a lower bus voltage compared with the bus voltage of the sinewave converter. The voltage dip ride-through capability of the converter with programmable damping resistance is significantly improved due to the immediate change of the grid current at the start of the voltage dip. 


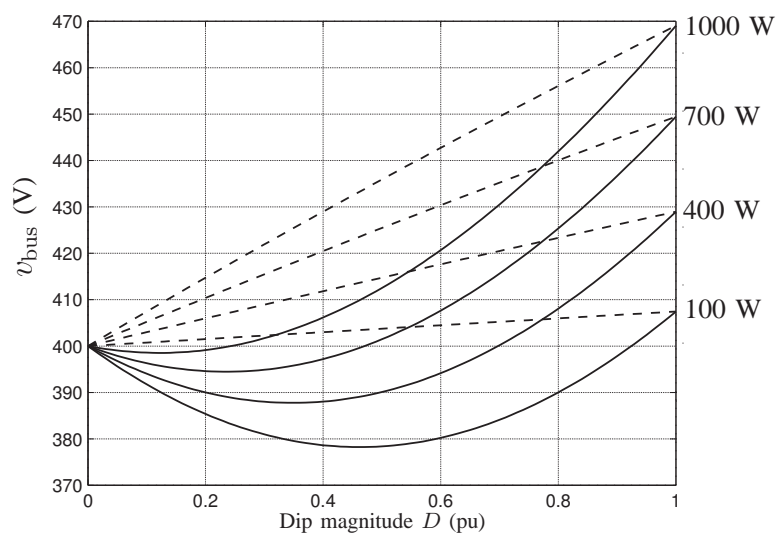

Figure 4: Bus voltage variations vs. dip magnitude and transmitted power without bus voltage controller during a $50 \mathrm{~ms}$ dip. Converter with programmable damping resistance: full black lines, Sinewave converter: dashed black lines

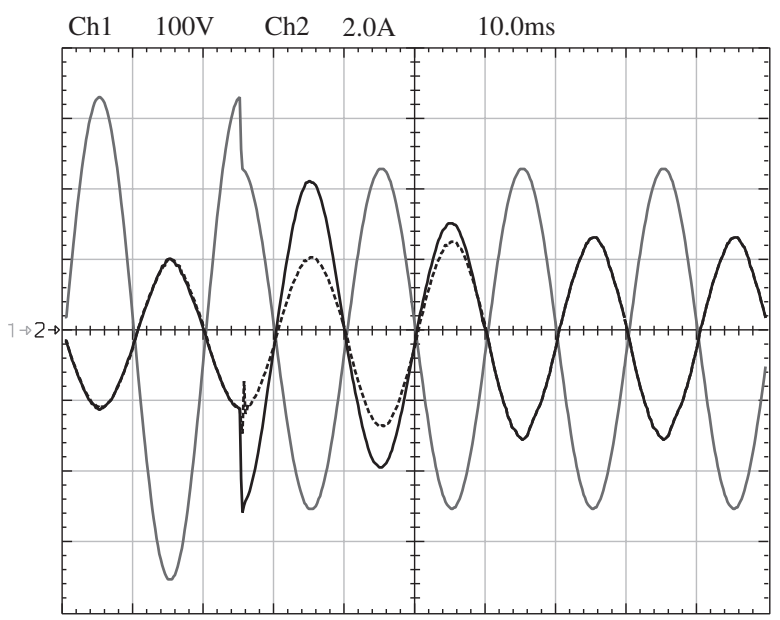

Figure 5: Influence of the bus voltage controller during a voltage $\operatorname{dip}\left(D=0.3\right.$ and $\left.t_{\text {dip }}=120 \mathrm{~ms}\right)$. Grid voltage: full gray line, grid current of the converter with programmable damping resistance: full black line, grid current of the sinewave converter: dashed black line.

\section{Bus voltage controller}

The duration of most voltage dips does not allow to neglect the influence of the bus voltage controller. The bus voltage controller will adapt the emulated fundamental conductance $g$ in order to control the disturbed bus voltage. The grid current of the sinewave converter during bus voltage controller saturation will remain sinusoidal. The amplitude of the sinewave will increase during the dip due to the action of the bus voltage controller. As can be seen in Fig. 5, the steady-state amplitude is reached 3 grid periods after the start of the grid voltage dip. The grid current of the converter with programmable damping resistance increases at the start of the dip due to the change of the reference value $i_{\mathrm{L}}^{*}$, and is then gradually decreased under influence of the bus voltage controller. The total energy exchanged with the utility grid during the voltage dip is increased due to the control algorithm with damping resistance.

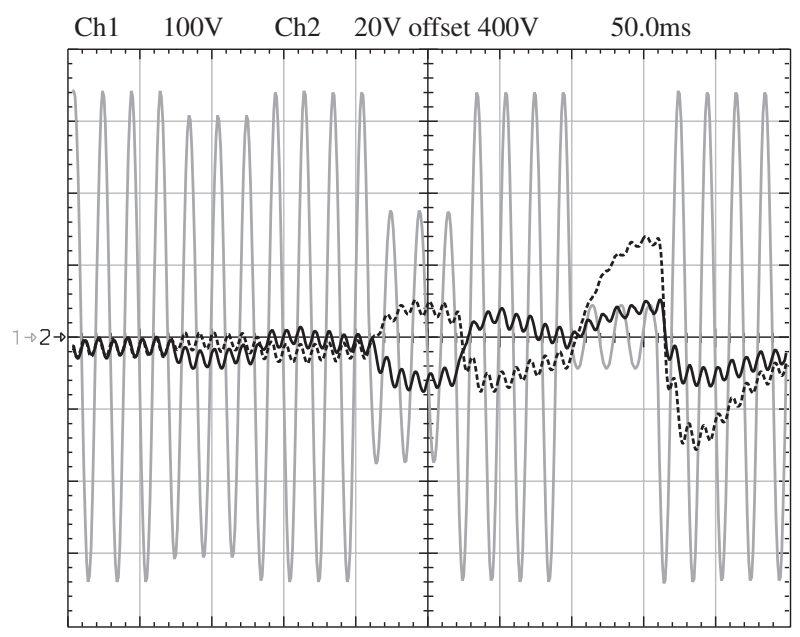

Figure 6: Bus voltages of the converter with programmable damping resistance (full black lines) and the sinewave converter (dashed black lines) during a series of increasing grid voltage dips (full gray lines)

\section{Experimental voltage dip ride-through ca- pability test}

To test the voltage dip ride-through capability, the linear amplifier is programmed to generate a series of dips with increasing dip magnitude. To obtain the dc power, an adjustable resistor is used in series with a voltage source. Adjustment of the resistor value at the dc side, yields a variation of power injected in the utility grid in steady-state conditions. The bus voltage $v_{\mathrm{dc}}(t)$ and the line voltage $v_{\mathrm{g}}(t)$ are depicted in Fig. 6 as full and dashed lines respectively, for a dc power of 500 Watt.

The start of the dips is delayed until the converter is in steady state and are synchronized with the zero crossings of the grid voltage, as can be seen in the bus voltages depicted in Fig. 6.

The experimental results validate the superior voltage ridethrough capability of the converter with a programmable damping resistance. The sinewave converter can be found to experience higher bus voltages during voltage dips as compared to the converter with programmable damping resistance. As can be seen in Fig. 6, the bus voltage of the converter with programmable damping resistance is kept lower due to the implementation of the algorithm with programmable damping resistance.

\section{Conclusion}

This paper describes the improvement of the voltage dip ride-through capability of a full-bridge bidirectional converter by means of the implementation of an alternative current control strategy. The current control strategy with a programmable damping resistance has been compared to the classical sinewave control strategy. In both current control strategies the effects of a voltage dip have been analysed, the response of the converters has been 
compared and the effects on the voltage dip ride-through capability have been described. The converter with programmable damping resistance, which was originally designed to provide damping for harmonic oscillations in the utility grid, has showed a significantly better voltage dip immunity. The impact of implementing the alternative current control strategy was experimentally verified using a full-bridge converter for grid connection of distributed generation units.

\section{References}

[1] M. F. McGranaghan, D. R. Mueller, and M. J. Samotyj, "Voltage sags in industrial systems," IEEE Trans. Ind. Applicat., vol. 29, no. 2, pp. 397-403, Mar./Apr. 1993.

[2] M. H. J. Bollen, Understanding power quality problems, ser. Power Engineering. IEEE press, 2000.

[3] F. A. Magueed, A. Sannino, and J. Svensson, “Transient performance of voltage source converter under unbalanced voltage dips," in Proc. IEEE Power Electr. Spec. Conf. (PESC'04), Aachen, Germany, June 20-25, 2004, pp. 1163-1168.

[4] A. Sannino, M. H. J. Bollen, and J. Svensson, "Voltage tolerance testing of three-phase voltage source converters," IEEE Trans. Power Delivery, vol. 20, no. 2, pp. 1633-1639, Apr. 2005.
[5] J. Morren, S. W. H. de Haan, and J. A. Ferreira, "Distributed generation units contributing to voltage control in distribution networks," in 39th Int. Universities Power Engineering Conf. (UPEC'04), Bristol, UK, Sept. 6-8, 2004.

[6] K. J. P. Macken, M. H. J. Bollen, and R. J. M. Belmans, "Mitigation of voltage dips through distributed generation systems," IEEE Trans. Ind. Applicat., vol. 40, no. 6, pp. 1686-1693, Nov./Dec. 2004.

[7] "Grid code," E.ON Netz GmbH, Tech. Rep., Apr. 2006. [Online]. Available: http://www.eon-netz.com/Ressources/downloads/ ENENARHS2006eng.pdf

[8] S. B. Kjaer, J. K. Pedersen, and F. Blaabjerg, "A review of single-phase grid-connected inverters for photovoltaic modules," IEEE Trans. Ind. Applicat., vol. 41, no. 5, pp. 1292-1306, Sept./Oct. 2005.

[9] W. R. Ryckaert, K. De Gussemé, D. M. Van de Sype, L. Vandevelde, and J. A. Melkebeek, "Damping potential of single-phase bidirectional rectifiers with resistive harmonic behaviour," IEE Proc. Electr. Power Appl., vol. 153, no. 1, pp. 68-74, Jan. 2006.

[10] B. Renders, K. De Gussemé, W. R. Ryckaert, and L. Vandevelde, "Input impedance of grid-connected converters with programmable harmonic resistance," IET Electr. Power Appl., accepted for publication. 